Crítica e Sociedade: revista de cultura política, Uberlândia, v. 9, n. 1, 2019.

\title{
Mulher negra congadeira: engajamento cultural e ativismo negro para além das grandes metrópoles
}

\section{“Congadeira" black woman: cultural engagement and black activism beyond the big cities}

Claudelir Corrêa Clemente 1

\section{Resumo}

Este artigo discute o protagonismo das mulheres negras habitantes do Triângulo Mineiro, em especial aquelas engajadas na manifestação cultural afro-brasileira denominada congada. Conhecida pelo seu aspecto festivo e religioso, a congada reúne um contingente significativo de mulheres negras, fornecendo ao conhecimento científico exemplos singulares de empoderamento feminino e ativismo negro em cidades do interior do país. Numa perspectiva antropológica, este artigo ancora-se na observação etnográfica realizada na comunidade congadeira de Uberlândia. Sua análise problematiza o engajamento feminino na congada como possibilidade de empoderamento da mulher negra, incentivando seu protagonismo e as colocando diante de questões prementes de combate ao racismo e ao sexismo. Entendo que há nas experiências dessas mulheres um feminismo negro que busco realçar com o apoio das reflexões das intelectuais negras Kimberlé Crenshaw, Lélia Gonzalez e Sueli Carneiro.

Palavras chave: Congado, Feminismo Negro, Protagonismo

\begin{abstract}
This article discusses the role of black women inhabitants of the Triângulo Mineiro, especially those engaged in the Afro-Brazilian cultural manifestation called congada. Known for its festive and religious aspect, the congada brings together a significant number of black women, providing scientific knowledge with unique examples of female empowerment and black activism in cities in the interior of the country. From an anthropological perspective, this article is anchored in the ethnographic observation carried out in the congadeira community of Uberlândia. His analysis problematizes female engagement in congada as a possibility for the empowerment of black women, encouraging their protagonism and placing them in the face of pressing issues of combating racism and sexism. I understand that in these women's experiences there is a black feminism that I seek to highlight with the support of the reflections of black intellectuals Kimberlé Crenshaw, Lélia Gonzalez and Sueli Carneiro.
\end{abstract}

Keywords: Congado, Black Feminism, Protagonism.

\footnotetext{
${ }^{1}$ É professora de Antropologia na Universidade Federal de Uberlândia em Minas Gerais, realizou pós-doutoramento na École Hautes Études en Sciences Sociales (2016). Possui doutorado em Ciências Sociais com concentração em Antropologia pela Pontifícia Universidade Católica de São Paulo
} 


\section{Introdução}

Nosso ponto de partida neste artigo é o protagonismo das mulheres negras habitantes do Triângulo Mineiro, em especial aquelas engajadas na manifestação cultural afro-brasileira denominada congada.

Expressivamente importante para os afro-brasileiros dessa região de Minas Gerais, a congada reúne um contingente significativo de mulheres negras, fornecendo ao conhecimento científico exemplos singulares de empoderamento feminino e ativismo negro em cidades do interior. Nesses municípios a força econômica está assente no potencial rural, espelhando uma urbanidade erguida através do capital do agronegócio.

A congada é mais conhecida pelo seu aspecto festivo, de celebração de cunho católico, no mês de outubro, para Nossa Senhora do Rosário e São Benedito. É constituída por ternos (grupos) de congado que localmente são denominados congos, marinheiros, marujos e moçambiques. Esses ternos organizam um calendário de visitas fraternas entre eles, mas também atividades mais amplas envolvendo congadeiros/as e sociedade em geral, tais como terços, bingos, leilões e ações educativas (palestras, oficinas) em torno da cultura congadeira. São nesses momentos que antecedem e precedem a preparação da festa que se observa o cultivo de ações de empoderamento negro.

As primeiras manifestações congadeiras datam dos tempos de escravização das populações negras no Brasil colonial. Ao longo da história social do Triângulo Mineiro essa celebração constituiu-se como uma espécie de lócus cultural onde são cultivados valores da cultura negra e pelo qual a maioria dos afrodescendentes, principalmente os de origem popular, alimentam sua consciência racial. A congada reflete a memória da escravização, o racismo, as dificuldades cotidianas e a segregação socioespacial da negritude, mas também a fé, as superações, os laços étnicos, a esperança e as conquistas. Em especial para a mulher negra, que no ambiente das práticas congadeiras experimenta formas de empoderamento feminino, ativismo, autoestima e valorização racial. Ela é chamada a exercer uma ação importante nos processos de valorização, socialização e reconhecimento da cultura negra. $\mathrm{E}$ isso lhe propicia uma vivência relacional profunda com os poderes locais, tais como as prefeituras, as escolas e as universidades, e os poderes das instâncias federais, como o Instituto do Patrimônio Artístico Nacional (Iphan). Tudo isso, de certa forma, instiga seu protagonismo: paulatinamente, por meio dessas ações e atuações, as mulheres negras vão construindo seu lugar político na sociedade. 
Meu primeiro contato com as mulheres negras do Triângulo Mineiro ocorreu em 2010, por meio de um conjunto de pesquisas antropológicas em torno de duas temáticas: quilombos em área de mineração e práticas culturais urbanas. No processo de execução da pesquisa urbana, fui surpreendida pela congada cujo som dos tambores passei a escutar durante o ano, com maior intensidade entre agosto e outubro. No anoitecer, durante alguns dos meus trajetos pela cidade de Uberlândia, aqueles sons com ritmos africanos e afro-brasileiros se faziam presentes.

Minha curiosidade me levou aos seus espaços e logo passei a fazer amizade com as pessoas envolvidas naquela sonoridade. Percebi que tudo aquilo estava ligado a uma devoção. Passei a escutar suas rezas de terço, suas conversas; partilhar almoços em que se serve congalinhadas; acompanhar suas visitas a congadeiros de outros municípios, seus bingos e suas palestras. Por fim, me vi fazendo antropologia urbana através da observação da congada. Em todos esses momentos havia muitas mulheres e elas manifestavam uma alegria e uma devoção que transmitiam força e dignidade. No decorrer da etnografia fui me aproximando e buscando compreender a sua altivez.

Numa perspectiva antropológica, este artigo ancora-se na etnografia dessa convivência com as congadeiras. Sua análise problematiza o engajamento feminino na congada como possibilidade de empoderamento da mulher negra, incentivando seu protagonismo e a colocando à frente das questões prementes de combate ao racismo e ao sexismo. Entendo que há nas experiências dessas mulheres um feminismo negro que busco realçar tendo como apoio as reflexões das intelectuais negras Kimberlé Crenshaw, Lélia Gonzalez e Sueli Carneiro.

\section{A cidade congadeira}

A mesorregião do Triângulo Mineiro e Alto Paranaíba é, sobretudo, um espaço que reúne antigas comunidades negras, urbanas e quilombolas. Muitos dos seus membros são engajados em culturas ancestrais como a congada, festejo afro-brasileiro com mais de 140 anos de existência e que se mantém vivo em várias cidades do estado de Minas Gerais.

Nessa mesorregião,

[...] a cultura negra adquiriu historicamente papel central nas inúmeras práticas culturais populares verificadas nos diferentes municípios, vilas e vilarejos locais (...) Os primeiros registros históricos da cultura afro-brasileira no Triângulo Mineiro associam-se à descoberta de jazidas de ouro e diamantes no interior de Goiás e Mato Grosso, ainda no século XVIII. A mineração, que por essa época se desloca para o Centro-Oeste, foi a principal responsável pela formação dos primeiros arraiais (SILVA, 2013, p.13/14). 
Em suas análises, Paul Gilroy (2008) nos leva a compreender que as experiências sociais negras portam um dinamismo que corrói a dominação cotidiana e, quando menos se espera, ouvimos seus sons, nos deparamos com sua cultura e nos surpreendemos com suas lutas sociais.

Em Uberlândia essa força cultural negra congadeira é visível. A cidade tem um papel importante nesse universo, pois possui uma congada com mais de 140 anos, a primeira da região a ser reconhecida, em 2008, como Patrimônio Imaterial Municipal².

Sua origem tem matriz banto-africana e influência católica, tendo emergido no contexto brasileiro colonial em que crenças, fé, religiões e devoções eram intensamente praticadas por povos africanos escravizados, lusitanos e indígenas. Em meio a esse grande laboratório religioso, configurou-se esse tipo de celebração negra que louva seus santos - em Uberlândia, particularmente, Nossa Senhora do Rosário e Santa Efigênia, São Benedito - através de grupos musicais de base percussiva, autodenominados ternos de congos: catupés, congos, marinheiros, marujos e moçambiques.

Em Minas Gerais é um evento significativo do calendário religioso dedicado à devoção dos santos católicos e organizado por Irmandades de Homens Negros ${ }^{3}$, organizações religiosas de caráter leigo que desempenharam papel especial durante a colonização brasileira. Nesse período, a vinculação social via irmandades promovia entre os negros urbanos, principalmente os alforriados, um tipo de ajuda mútua, possibilitando-lhes locais de encontros, nos quais escondiam as cerimônias religiosas propriamente africanas e, por vezes, organizavam revoltas. Em síntese, a participação nessas organizações permitia aos negros encontrar um alento frente à perversidade do sistema escravocrata, que gerou para o negro uma vida social estigmatizada mesmo após o seu término.

Uma das primeiras irmandades do Triângulo Mineiro e Alto Paranaíba é a de Nossa Senhora do Rosário e São Benedito de Uberlândia (INSRSB), oficializada em 1916. De acordo com Senhor Deny Nascimento, atual presidente da irmandade, no entanto, as celebrações da congada já ocorriam desde 1874, tendo sido o seu avô, ainda na condição de escravizado, o primeiro organizador desses louvores aos santos católicos.

Um elemento interessante é que, desde seu início, a INSRSB é composta de afrouberlandenses e de afrodescendentes advindos de outras regiões de Minas Gerais, em especial do Desemboque, Sacramento, Cruzeiro da Fortaleza, Patrocínio e Alto do Paranaíba. Entre as suas principais responsabilidades estão a organização dos ternos que compõem os festejos aos santos

2 O patrimônio histórico e cultural foi registrado por meio do Decreto no 11.321, de 29 de agosto de 2008. Prefeitura de Uberlândia.

3 Tambem denominadas de Irmandades Religiosas de Santos de Pretos.

Crítica e Sociedade: revista de cultura política, Uberlândia, v. 9, n. 1, 2019

ISSN: 2237-0579 
católicos e a preparação de todo o processo ritual da celebração a partir do mês de agosto, com as atividades de arrecadação para financiamento do desfile de ternos, e prossegue até a primeira quinzena de outubro, quando têm início a novena e os terços e ocorre a celebração final.

São entre 24 e 26 ternos que compõem atualmente a INSRSB de Uberlândia. Cada um deles segue esse calendário profano e religioso, cumprindo algumas obrigações sociais e religiosas em um espaço denominado quartel congadeiro. Trata-se de um local em que se reúnem todos os participantes do terno, cada qual desempenhando um papel: um capitão ou capitã (aquele/a responsável pelo terno), soldados (percussionistas e dançadores), madrinhas e as meninas da bandeira do terno.

Em Uberlândia, nos cinco meses que antecedem o mês de outubro, dedicado à celebração dos santos da congada (Nossa Senhora do Rosário, São Benedito e Santa Efigênia), os quartéis congadeiros reúnem devotos e simpatizantes para preparar a festa e exaltar seus laços sociais. Um conjunto de atividades é mais visível: campanhas, leilões e novenas são realizados para angariar fundos, mas, sobretudo, para fortalecer laços de sociabilidade. Nesses momentos a atuação feminina é imprescindível e é dela que provém a força que garante a manutenção do terno e, principalmente, de seu sentido étnico. São as mulheres que exaltam, cultivam e transmitem os valores da cultura ancestral congadeira, assim como reforçam a autoestima, a estética e o estilo de vida da congada.

É por meio dessa valorização e afirmação constantes da importância dos valores afrobrasileiros que comportamentos, cuidados corporais, opções de vestimentas, cabelo, unhas e pele reforçam a estética de conteúdo afro. Esse jeito de ser, esse estilo afro-brasileiro circula nas ruas da cidade, nos locais de trabalho, nas escolas e universidades, não se restringindo apenas ao momento da celebração aos santos.

A localização desses quartéis também me faz refletir sobre as condições de moradia da população negra uberlandense. A maioria de seus lares está nas periferias da cidade, confirmando uma segregação socioespacial que confina negras e negros e os obriga a uma convivência fora dos perímetros destinados às moradias de elite. Assim, todos os quartéis estão localizados na periferia, majoritariamente na própria casa da capitã ou capitão.

Sobre as relações entre segregação socioespacial e racismo, as análises de Lélia Gonzalez (2018, p. 201) ampliam a sua compreensão:

Desde a época colonial aos dias de hoje, percebe-se uma evidente separação quanto ao espaço físico ocupado por dominadores e dominados. O lugar natural do grupo branco dominante são moradias saudáveis, situadas nos mais belos 
recantos da cidade ou do campo e devidamente protegidas por diferentes formas de policiamento, que vão desde os feitores, capitães de mato e capangas etc. até a polícia formalmente constituída. Desde a casa grande ao sobrado até aos belos edifícios e residenciais atuais o critério tem sido o mesmo. Já o lugar natural do negro é o oposto, evidentemente: da senzala, às favelas, cortiços, invasões, alagados e conjuntos "habitacionais" (...) dos dias de hoje, o critério tem sido simetricamente o mesmo: a divisão racial do espaço. (...) Além disso, aqui também se tem a presença policial; só que não é para proteger, mas para reprimir, violentar e amedrontar.

Em Uberlândia, nesses espaços segregados concentram-se a população negra e os pobres. Lá se encontram barreiras ao acesso e uso dos serviços e equipamentos de educação, saúde, cultura e assistência social; o desemprego impera e, mesmo quando se trabalha, na maioria das vezes, é sob condições precárias e em locais distantes da moradia. São nessas periferias que o quartel congadeiro emerge como um espaço de vivência cultural, de reflexão, de possibilidades e de encontros. Ao reunir os membros de cada terno e seus amigos, o quartel experimenta no seu espaço relações sociais que promovem formas de socialização dos indivíduos nos valores da cultura negra congadeira.

Atualmente, vem se constituindo, para seus membros, também como um celeiro de projetos culturais e intelectuais cujos conteúdos simbólicos configuram sentidos e ações que rompem com o racismo e fomentam formas de ativismo negro. Congrega projetos e lutas políticas antirracistas e de afirmação étnico-racial.

\section{Cultivando a consciência racial}

É com base nos vínculos sociais constituídos em torno de suas práticas culturais que negras e negros de Uberlândia começam a se organizar para o enfrentamento do racismo. E a congada acaba sendo para a comunidade negra " [...] o prelúdio de sua organização institucional no espaço público. Organização que sempre foi instigada pelo conflito e luta pela inserção dos projetos político-sociais desse segmento na esfera pública” (BARBOSA, 2011, p.77).

Assim, um caminho de conscientização racial e organização política é traçado no bojo das relações sociais e da hetoregeneidade das experiências socioculturais da negritude uberlandense". Isso porque, de acordo com Barbosa (2011, p. 71),

[...] historicamente, percebe-se que os primeiros modos de organização social da comunidade negra de Uberlândia foram constituídos mediante os rituais religiosos dos festejos dos grupos da congada; em bailes realizados nos clubes criados exclusivamente para negros e negras, como o "Flor de Maio", 
"Caba-Roupa", "Alvorada", "Zanzibar", "Monte Líbano", "Concorde" e a presença maciça da referida comunidade nos blocos e escolas de samba que foram desenvolvidos a partir de 1928.

É nessa convivência que congadeiros fortalecem seus vínculos sociais e buscam compreensão e disposição para enfrentar o racismo. Aliando-se aos irmãos do samba, com os terreiros de fé de matriz africana e contribuindo na construção do movimento negro local.

O depoimento de uma das fundadoras do movimento negro uberlandense, Conceição Pereira Leal, concedido a Barbosa (2011), confirma que muitas foram as formas de sociabilidade negra que contribuíram para organização da luta antirracista no Triângulo Mineiro e, por consequência, em Uberlândia. Foi, como observa Conceição, um movimento estratégico, que iniciou:

[...] um processo de aproveitar tudo aquilo que a comunidade negra tinha como espaço de organização social. Local de sociabilidade da comunidade tornou-se fundamental para isso. Por exemplo, em Uberaba tinha o Clube Elite (...) em Ituiutaba o Palmeiras Clube que ainda existe até hoje, tem mais de 60 anos. Em Uberlândia foi decisivo as experiências vividas pelo Clube Alvorada, o Concorde, o Monte Líbano (que era uma consequência do antigo Caba-Roupa etc.). Esses espaços históricos de convívio social da comunidade negra foram fundamentais para unificação dos negros em Uberlândia. (apud BARBOSA, 2011, p. 73).

Foi nos anos 1980 que o movimento negro emergiu em Uberlândia, no lastro do processo de redemocratização, que interrompeu a onda de silêncio vivenciada no período ditatorial do pós64. De volta à democracia, o Brasil viu a irrupção de novos movimentos sociais, entre os quais o movimento negro, cuja marca era a autonomia e a contestação de situações excludentes. Constituíram-se num processo de auto-organização, reivindicando direitos e não trocando favores, como os do passado:

[...] era o surgimento de uma "nova sociabilidade" (sic) em associações comunitárias onde a solidariedade e a autoajuda se contrapunham aos valores da sociedade inclusiva; eram os "novos movimentos sociais", que politizavam espaços antes silenciados na esfera privada (SADER,1988, p.35-36).

Há um outro fator importante, a congada dessa região sempre atraiu pesquisadores da cultura negra e das relações étnico-raciais. Nos anos 1990, antropólogos, historiadores e sociólogos foram os primeiros a realçarem a importância de estudos sobre a manifestação congadeira, entre os quais destaco um projeto de 1996, intitulado Cultura Negra e segregação socioespacial em Uberlândia: 
um estudo sobre música e ritual', desenvolvido pelo antropólogo e historiador Jose Carlos Gomes da Silva. Esse trabalho colocou a congada uberlandense, em especial, nos horizontes científicos das universidades. A partir desse momento, os ternos passaram a receber muitos pesquisadores.

$\mathrm{Na}$ trilha de Marcel Mauss ${ }^{5}$, passou-se a observar que esse encontro entre a academia e a congada abriu um canal de trocas pelo qual circulam até os dias de hoje pessoas, palavras, eventos, ideias, projetos, dissertações, teses, políticas e amizades. As relações com a academia contribuíram para nutrir intelectualmente um campo reflexivo de problematizações sobre o racismo, algo já cultivado pelos congadeiros nos encontros e nas trocas do quartel e pelo movimento negro. Mas, com a entrada de pessoas ligadas à educação superior, houve uma ampliação do escopo das discussões acerca dos problemas que afetam a negritude.

Esse encontro é importante em razão de o racismo brasileiro contra negras e negros basearse numa perversa etiqueta de distanciamento social e uma diferenciação aguda de status e de possibilidades econômicas convivendo com uma suposta cidadania para todos e indiferenciação formal: "[...] um sistema muito complexo e ambíguo de diferenciação racial, baseado principalmente em diferenças fenotípicas e cristalizado num vocabulário cromático" (GUIMARÃES, 1995, p.27/28). Para desvelar esse sistema é preciso refletir conjuntamente e incorporar também os estudos acadêmicos.

Há, ainda, outro fator que deve ser considerado, o da concentração perversa e distribuição desigual da riqueza brasileira, que afeta majoritariamente as pessoas pardas e pretas. Esse processo de desigualdade tem suas origens na colonização, na escravidão e na consolidação do capitalismo. E é algo que se reproduz na contemporaneidade. Os malefícios do imbricamento entre colonialismo, racismo e capitalismo não estão só no passado distante, mas no presente. Desvelar a suposta democracia racial brasileira é um fator importante para aqueles que se empenham na luta antirrascista.

Desse enlace entre congada, movimento negro e academia emergiu uma pauta significativa de ações importantes para o combate ao racismo. Desse contexto afloraram e ganharam densidade as discussões sobre a Lei 10.639/03, que versa sobre o ensino de história e cultura afro-brasileira, bem como emergiram as ações de fortalecimento dos Núcleos de Estudos Afro-Brasileiros (NEAB), criados no início dos anos 2000, e de incentivo à entrada de congadeiras e congadeiros na universidade pública. Todas essas iniciativas criaram as condições para ampliar o que estou

\footnotetext{
${ }^{4}$ Projeto financiado pela Fapemig. Silva é professor da Universidade Federal de São Paulo (Unifesp).

${ }^{5}$ Marcel Mauss é um clássico da teoria social, autor de Ensaio sobre o dom, obra que analisa o princípio de reciprocidade (dar, receber e retribuir), fundante da vida social.

Crítica e Sociedade: revista de cultura política, Uberlândia, v. 9, n. 1, 2019

ISSN: 2237-0579
} 
chamando de campo reflexivo congadeiro, processo que se dá também com a maior inserção dos participantes da congada nas discussões mais amplas sobre o combate ao racismo e que envolvem outros segmentos antirracistas da sociedade uberlandense.

Assim, não tardou para a inserção institucional de congadeiros na política municipal. Em exemplo mais recentemente, em 2013 Ramon Rodrigues ${ }^{6}$, congadeiro do terno Moçambique de Belém, formado em administração, tornou-se titular da Superintendência da Igualdade Racial (Supir) na gestão do então prefeito Gilmar Machado. Em conjunto com o Núcleo de Estudos AfroBrasileiros da Universidade Federal de Uberlândia e o movimento negro local, a Supir criou o Fórum de Promoção da Igualdade Racial de Uberlândia (Fopir), do qual muitos/as congadeiros/as participaram ativamente, contribuindo para o fortalecimento de pautas antirracistas.

Nesse sentido, é possível afirmar que, desde o final dos anos de 1990, a congada foi sendo abraçada por instituições e por movimentos sociais que denunciam o racismo. Isso vem permitindo um crescente processo de conscientização racial que favorece as congadeiras.

\section{Subvertendo a condição da mulher negra}

Em recente encontro feminista realizado no Rio de Janeiro, nossa participação causou reações contraditórias. Até aquele momento, tínhamos observado uma sucessão de falas acentuadamente de esquerda, que colocavam uma série de exigências quanto à luta contra a exploração da mulher, do operariado, etc., etc. A unanimidade das participantes quanto a essas denúncias era absoluta. Mas no momento em que comecei a falar do racismo e suas práticas em termos de mulher negra, já não houve mais unanimidade. Nossa fala foi acusada de emocional por umas e revanchista por outras; todavia, as representantes de regiões pobres nos entenderam perfeitamente (GONZALEZ, 2018, p.48).

O Brasil atual não superou as grandes disparidades raciais de renda, inserção qualificada no mercado de trabalho, educação, saúde, expectativa de vida e outros indicadores. E isso atinge diretamente a mulher negra: "Ser negra e mulher no Brasil é ser objeto de tripla discriminação, uma vez que os estereótipos gerados pelo racismo e sexismo as colocam no mais baixo nível de opressão" (GONZALEZ, 2018, p. 44). Em síntese, exposta a um sistema de classificação social derivado do patriarcado e do racismo que enaltece a primazia das populações brancas, a mulher negra está sujeita à condição de subalternidade, à vivência constante da pobreza, à discriminação, à violência e à vulnerabilidade, em todas as dimensões de suas experiências sociais.

Muitas mulheres negras em coletividade, no entanto, têm construído outros presentes e

${ }^{6}$ Sobre a posse do superintendente ver http://uipi.com.br/destaques/destaque-2/2013/10/18/ramon-rodrigues-e-onovo-superintendente-da-igualdade-racial/

Crítica e Sociedade: revista de cultura política, Uberlândia, v. 9, n. 1, 2019

ISSN: 2237-0579 
futuros mais promissores para seu segmento. O movimento de mulheres negras, que é heterogêneo e plural (COLLINS, 2017), tem um papel importante de conscientização racial no processo de compreensão dessas condições de subalternização.

Desde que o feminismo negro no Brasil passou a questionar a dominação sobre esse segmento, o movimento ampliou suas possibilidades de luta. Destaco, porém, que este não foi um processo fácil, pois “[...] o feminismo esteve, também, por longo tempo, prisioneiro da visão eurocêntrica e universalizante das mulheres" (CARNEIRO, 2003, p.118). A autora argumenta que, ao politizar as desigualdades de gênero,

[...] o feminismo transforma as mulheres em novos sujeitos políticos. Essa condição faz com esses sujeitos assumam, a partir do lugar em que estão inseridos, diversos olhares que desencadeiam processos particulares subjacentes na luta de cada grupo particular. Ou seja, grupos de mulheres indígenas e grupos de mulheres negras, por exemplo, possuem demandas específicas que, essencialmente, não podem ser tratadas, exclusivamente, sob a rubrica da questão de gênero se esta não levar em conta as especificidades que definem o ser mulher neste e naquele caso. Essas óticas particulares vêm exigindo, paulatinamente, práticas igualmente diversas que ampliem a concepção e o protagonismo feminista na sociedade brasileira, salvaguardando as especificidades (CARNEIRO, 2003, p. 119).

Quando dirigimos nossa reflexão para a experiência das mulheres negras congadeiras, nascidas e criadas em cidades rurais sob o comando do agronegócio, visualizamos o árduo processo de conscientização racial. Isso porque essa reflexão obriga ao enfrentamento de uma sociedade ancorada fortemente no poder de homens brancos.

Mas sabemos que o contingente negro de Uberlândia solidificou um platô antirracista cuja base é sustentada por vínculos sociais de longa data e por muitas parcerias. Suas redes de cultura e política servem de base para as congadeiras. É nos percursos e encontros da congada que as mulheres tomam contato com a pauta política negra contra o racismo. Muitas, a princípio, atentas e ouvintes; algumas já inseridas no Fórum de Promoção da Igualdade Racial de Uberlândia, no movimento negro local. Todas sempre nutrindo-se e conscientizando-se da existência do racismo.

Entre esses encontros com outras experiências de luta negra, destaco o contato das congadeiras, em 2015, com o processo de organização da Marcha das Mulheres Negras. Isso teve um papel significativo na vida dessas mulheres, pois não podemos nos esquecer que elas são habitantes de cidades interioranas, distantes dos grandes centros urbanos em que o feminismo negro floresceu e se fortaleceu. Nesse sentido, a Marcha permitiu a elas se aproximarem da reflexão e da atmosfera política do feminismo negro, suas reivindicações, mas também sua epistemologia 
negra. E isso foi importante porque a mulher negra vive discriminações ocultas no atarefado cotidiano que muitas vezes lhes são imperceptíveis, o que a torna mais vulnerável à opressão. Por isso, o contato com a luta e com as análises do feminismo negro permite compreender conceitos como de interseccionalidade, um conhecimento importante na superação do racismo.

Sobre interseccionalidade, Kimberlé Crenshaw (2002, p. 177) afirma:

A associação de sistemas múltiplos de subordinação tem sido de vários modos: discriminação composta, cargas múltiplas ou como dupla ou tripla discriminação. A interseccionalidade é uma conceituação do problema que busca capturar as consequências estruturais e dinâmicas da interação entre dois ou mais eixos da subordinação. Ela trata especificamente da forma pela qual o racismo, o patriarcalismo, a opressão de classe e outros sistemas discriminatórios criam desigualdades básicas que estruturam as posições relativas de mulheres, raças, etnias, classes e outras. Além disso, a interseccionalidade trata da forma como ações e políticas específicas geram opressões que fluem ao longo de tais eixos, constituindo aspectos dinâmicos ou ativos do desempoderamento.

De grande importância nos estudos de gênero e raça, a interseccionalidade contribui para a construção de um conhecimento da discriminação vivida por mulheres negras na sociedade. Isso porque, assim como é real o fato de que todas as mulheres estão sujeitas ao peso da discriminação de alguma forma, também é verdade que há outros fatores relacionados “[...] a suas identidades sociais, tais como classe, casta, raça, cor, etnia, geração, religião, origem nacional e orientação sexual" (CRENSHAW, 2002, p. 173), acentuando as diferenças que influenciam diferentemente na forma como vários grupos de mulheres vivenciam a discriminação.

Conceitos como a de intersecccionalidade dialogam com as vivências das mulheres negras porque remetem a algo que é experimentado por elas no cotidiano: a discriminação racial, o machismo, o trabalho desqualificado e mal pago, a moradia precária em bairros insalubres e distantes, as filhas e os filhos afrodescendentes desrespeitados na sua condição infantil ou juvenil. Um cotidiano de múltiplas discriminações que passaram a ser consideradas pela ação ativista das próprias mulheres negras. Nessa perspectiva, mais uma vez me apoio nas reflexões de Gonzalez (2018, p. 192): "O fato é que, enquanto mulher negra, sentimos necessidade de aprofundar nessa reflexão, em vez de continuarmos na reprodução e repetição dos modelos que nos eram oferecidos". O feminismo negro, ao enegrecer o feminismo, aproximou a luta feminista das mulheres negras e as inseriu no campo das reflexões negras, constituído majoritariamente por elas.

Antônia Aparecida Rosa é uma dessas mulheres negras congadeiras. Professora e capitã do terno Marinheiro de Nossa Senhora do Rosário, foi uma das primeiras mulheres a assumir esse cargo em um terno da congada de Uberlândia, função predominantemente masculina. Filha mais 
velha de uma família congadeira chefiada pela mãe, que também foi capitã de terno, Antônia assumiu importante função após o falecimento de sua mãe. Assim, com o terno, abriu-se uma possibilidade de realizar ações que também refletissem a condição de opressão que historicamente acompanha a experiência negra.

Certa vez, numa de nossas conversas, narrou a discriminação contra negras, a partir de uma experiência vivida por sua mãe, que trabalhou durante muito tempo como doméstica. Muitas vezes, nos idos dos anos 1970 e 1980, nos seus trajetos entre a casa e o trabalho, ela passou pelo entorno da Universidade Federal de Uberlândia. Segundo Antônia, a mãe teria um acesso mais rápido às casas em que trabalhava se passasse por dentro da UFU, mas sentia-se intimidada pelos olhares das pessoas ao vê-la: uma mulher negra andando pelo campus universitário?

Esses são os olhares do racismo porque expressam a maneira como brancos fomentam a discriminação racial fixando-se nas características fenotípicas. As análises de Guimarães (1995, p. 34) permitem compreender a fixação no fenótipo, na cor de pele:

[...] não há nada espontaneamente visível na cor da pele, no formato do nariz, na espessura dos lábios ou dos cabelos, ou mais facilmente discriminatório nesses traços do que em outros, como o tamanho dos pés, a altura, a cor dos olhos ou a largura dos ombros. Tais traços só têm significado no interior de uma ideologia preexistente (para ser preciso: de uma ideologia que cria os fatos ao relacioná-los uns aos outros), e apenas por causa disso esses traços funcionam como critérios e marcas classificatórios. Em suma, alguém só pode ter cor e ser classificado num grupo de cor se existe uma ideologia na qual a cor das pessoas tem algum significado. Isto é, as pessoas têm cor apenas no interior de ideologias raciais, stricto sensu.

No Brasil, esse sistema de hierarquização social - que consiste em gradações de prestígio formadas por classe social (ocupação e renda), origem familiar, cor e educação formal - funda-se nas dicotomias que por três séculos sustentaram a ordem escravocrata: elite/povo e brancos/negros apresentam uma atualidade e se reforçam mutuamente, simbólica e materialmente.

Mesmo num contexto de ideologia racista, contudo, a mãe de Antônia sonhou para filha um projeto de vida que subverteria aquela condição negra de constrangimento frente a um mundo que, apesar de ter sido construído com a contribuição de negras e negros, era-lhes negado justamente em suas benfeitorias modernas: igualdade, fraternidade, liberdade, respeito à diferença, acesso a todos os níveis de educação e dignidade. Antônia conseguiu realizar o sonho materno, constituindo uma família congadeira e, desapontando os olhares racistas, se formando pedagoga na Universidade Federal de Uberlândia e tornando-se mais tarde superintendente da Supir Uberlândia, na gestão de Gilmar Machado. Nesse cargo implantou vários cursos de capacitação da 
Promoção da Igualdade Racial, Políticas Públicas e Controle Social, promovido pela prefeitura e realizado no Centro Municipal de Estudos e Projetos Educacionais Julieta Diniz (Cemepe).

O sonho que sua mãe sonhou para ela parece basear-se na concepção congadeira do papel da mulher no terno. É a própria Antônia quem descreve tal papel:

A mulher tem o papel de alimentar espiritualmente e socialmente o terno. Elas são a força do terno. As madrinhas em específico devem zelar pelo grupo. Alimentação de fé, do corpo e do espírito. Então, sabe? Esse papel é o papel central da madrinha. Ela organiza a festa, organiza meninas da bandeira, aconselha a todos, é orientadora. Organiza espiritualmente. A gente fala muito assim: que qualquer fato negativo espiritual que aconteça de negativo com o terno é a madrinha da bandeira que está na frente com as meninas das bandeiras no sentido de proteção. Quer dizer, acaba que o papel da mulher, olha só, é um grande papel: ela é protetora de todo o terno! O primeiro contato que todo mundo [o público dos festejos] tem é com as mulheres do terno. Elas filtram esses contatos.

Estabeleço uma interpretação desse relato para compreender como se pode projetar visões antirracistas mesmo não as constituindo através de conceitos científicos. Nesse sentido, penso que a mãe de Antônia desatou para filha as amarras do racismo; protegeu-a estando lado a lado com ela, como as madrinhas da congada ao lado das meninas da bandeira que seguem em desfile, nas ruas de Uberlândia, sob os olhares racistas, que deixam para trás, cumprindo sua missão religiosa e afirmando a dignidade das mulheres negras. Antônia continua seguindo e ultrapassando os racistas. Hoje aposentada, coordena voluntariamente a Casa Graça do Aché, uma instituição vinculada à UFU.

Iara Aparecida Ferreira, do terno Moçambique Estrela Guia, também é uma dessas mulheres negras que lutam por melhores condições de vida para os afro-brasileiros. Incentivadora cultural, formada em serviço social, ela vem fazendo um trabalho sociocultural e educativo para além do que já realiza no terno de congado nas festividades em louvor à Nossa Senhora do Rosário e São Benedito. Tem promovido e produzindo cultura, especialmente para o público infanto-juvenil de Uberlândia, onde fundou o Projeto Pró-Mirim Estrela Guia do Amanhã, de incentivo à cultura e qualificação de adolescentes e seus pais para o mercado de trabalho por meio de dança, teatro, música, artesanato, aulas práticas e teóricas pedagógicas de cultura afro-brasileira e oficinas com minicursos para a formação baseada na tradição congadeira. Iara é também assessora especial da Secretaria Municipal de Cultura e assistente social na Secretaria de Desenvolvimento Social e Trabalho de Minas Gerais.

Há um contigente significativo de congadeiras cujas trajetórias assemelham-se às de 
Antônia e Iara, que em razão dos limites deste artigo, serão contempladas em outras formas de publicação. Para o momento, é importante destacar que, a despeito da inserção social que obtiveram, ambas sabem que o empoderamento de que desfrutam hoje é tributário de um trabalho que começou na vivência congadeira.

\section{Considerações finais}

Ao longo deste artigo a prática congadeira foi definindo-se como um elemento que promove a coesão das populações negras do Triângulo Mineiro e Alto Paranaíba. Prática ancestral, a congada tem esse potencial agregador que ganha mais evidência entre o período de preparação dos festejos até sua celebração final. Nesse momento as populações negras da mesorregião engajadas na cultura congadeira desencadeiam um processo intenso de deslocamentos intermunicipais, intrabairros e interbairros, configurando um tipo de cartografia negra dentro do território dominado pelo agronegócio.

Esse potencial de agregar pessoas permitiu aos congadeiros a participação no processo de criação do movimento negro local. Também trouxe para os espaços da Congada, os quartéis congadeiros, pessoas simpáticas à cultura negra, em especial os pesquisadores e professores vinculados ao espaço universitário.

Desses encontros emergiu um campo reflexivo do qual congadeiros e demais parceiros nutrem-se do pensamento antirracista em que se potencializa a amizade e a solidariedade negra, provocando rupturas no racismo estrutural. Suscitando uma micropolítica que se revela macro, fomentando uma solidariedade que liga entre si os homens e as mulheres que se encontram para festejar santos e antepassados, mas sobretudo constituir agendas com demandas políticas que visam a ampliar os direitos das populações negras.

Nutridos de fé, de política e solidariedade organizam-se e reivindicam nos espaços institucionais de negociação dos poderes locais, tais como as prefeituras, escolas e universidades, e dos poderes federais suas pautas negras.

Nesse processo a mulher tem um papel fundamental. São as congadeiras que exaltam, cultivam e transmitem os valores da congada. É através dessa valorização do ser congadeiro e afirmação constantes da importância dos valores afro-brasileiros que elas encontram elementos para fazer valer os direitos da população negra. A atitude dessas mulheres expressa uma ação política que não é constituída, inicialmente, nas relações que envolvem partidos políticos e disputas 
pelo Estado. Antes, resulta de um trabalho feminino paulatino que incentiva afrodescendentes congadeiros a engajar-se culturalmente ao seu terno, à sua gente, à sua história.

Nesse sentido, as mulheres realçam em seu protagonismo que as manifestações culturais congadeiras constituem também estratégias de afirmação da identidade étnica, engendram uma rede de apoio social e possibilidades de constituição de um campo negro, uma complexa rede social permeada por aspectos multifacetados: mulheres negras, trabalhadoras, intelectuais, mas também congadeiras. Esse trabalho de afirmação étnica feito por elas no espaço do quartel é erguido por meio de ações e relações sociais que não têm aparentemente cunho político, mas têm o poder de arregimentar pessoas, reuni-las, organizá-las e transformá-las em agentes de causas sociais.

Digamos que a vivência no quartel congadeiro é a expressão de um "modelo comunitário de organização", que valoriza os laços interpessoais, a solidariedade, a ajuda mútua e a participação entre iguais. Características que se contrapõem às relações de dominação expressas no racismo, no sexismo, na exploração do capital rural, na segregação socioespacial urbana, na competitividade, no individualismo e na atomização da existência.

\section{Referências}

CARNEIRO, S. Mulheres em movimento. Estudos Avançado, São Paulo, v.17, n.49, p117-133, dez. 2003. Disponível em: <https://www.scielo.br/pdf/ea/v17n49/18400.pdf>. Acesso em: 10 ago. 2018.

COLLINS, P. H. O que é um nome? Mulherismo, Feminismo Negro e além disso. Cadernos Pagu, Campinas (SP), n. 51, e175118, $2017 . \quad$ Disponível em: <http://www.scielo.br/pdf/cpa/n51/1809-4449-cpa-18094449201700510018.pdf>. Acesso em: 20 maio 2018.

CRENSHAW, K. Documento para o encontro de especialistas em aspectos da discriminação racial relativos ao gênero. Revista Estudos Feministas, Florianópolis, v. 10, n. 1, pp. 171-188, 2002. Disponível em: <https://www.scielo.br/pdf/ref/v10n1/11636.pdf>. Acesso em: 14 out. 2018.

GILROY, P. O Atlântico negro: modernidade e dupla consciência. São Paulo: Ed. 34, 2008.

GONZALEZ, L. Primavera para as rosas negras: Leila Gonzalez em primeira pessoa. São Paulo: Diáspora Africana: Editora Filhos da África, 2018. (Coletânea org. e ed. Pela União dos Coletivos Pan-Africanistas).

GUATTARI, F. A revolução molecular. São Paulo: Brasiliense, 1986.

GUIMARAES, Antônio S. Racismo e antirracismo no Brasil. Novos Estudos CEBRAP, n.43,1995. 
SADER, E. Quando novos personagens entraram em cena. Rio de Janeiro: Paz e Terra, 1988.

SAMPAIO, A. C.; PACHECO, A. C. L. Mulheres griôs quilombolas: um estudo inicial sobre identidade de gênero e identidade étnica. Pontos de Interrogação - Revista de Crítica Cultural, Salvador, v. 5, n. 2, jul./dez. 2015.

SILVA, J. C. G. Congado e cultura centro-africana: marcas da ancestralidade. In: CLEMENTE, C. C.; SILVA, J. C. G. (Org.). Negros, cultura e vida urbana: estudos etnográficos sobre o congado. Uberlândia: RBDigital, 2013. 